\title{
New formulation of an old drug in hypertension treatment: the sustained release of captopril from cyclodextrin nanoparticles
}

This article was published in the following Dove Press journal:

International Journal of Nanomedicine

I4 May 20I I

Number of times this article has been viewed

\author{
Mariangela de Burgos M de \\ Azevedo' \\ Ljubica Tasic ${ }^{2}$ \\ Juliana Fattori ${ }^{2}$ \\ Fábio HS Rodrigues ${ }^{2}$ \\ Fabiana C Cantos' \\ Leandro P Ribeiro' \\ Vanice de Paula ${ }^{3}$ \\ Danielle lanzer ${ }^{3}$ \\ Robson AS Santos ${ }^{3}$ \\ 'Biopharmaceuticals and Hormones, \\ Center of Biotechnology, Instituto \\ de Pesquisas Energéticas e Nucleares \\ (IPEN), Sao Paulo, Brazil; ${ }^{2}$ Chemical \\ Biology Laboratory, Department \\ of Organic Chemistry, Instituto de \\ Química (UNICAMP), Sao Paulo, \\ Brazil; ${ }^{3}$ Hypertension Laboratory, \\ Department of Physiology and \\ Biophysics, Instituto de Ciências \\ Biológicas (ICB), Universidade \\ Federal de Minas Gerais (ICB-UFMG), \\ Minas Gerais, Brazil
}

Correspondence: Mariangela de Burgos M de Azevedo

Biopharmaceuticals and Hormones, Center of Biotechnology, IPEN,

Av. Lineu Prestes 2242, 05508-000,

Sao Paulo, Brazil

Tel +55 I । 3 I 339707

$\mathrm{Fax}+55$ II 31339018

Email mbmazevedo@ipen.br
Abstract: Captopril (CAP) was the first angiotensin I-converting enzyme (ACE) inhibitor to be developed and is widely used in hypertension treatment. On the other hand, cyclodextrins (CDs) are cyclic oligosaccharides whose cone-shaped cavity allows formation of noncovalent inclusion complexes with appropriately sized guest molecules, thus modifying guest physical, chemical, and biological properties. Herein, the physicochemical characterization and in vivo ACE inhibition evaluation of seven $\mathrm{CAP} / \mathrm{CD}$ complexes are reported. The inclusion complexes were prepared by spray-drying, freeze-drying, kneading, or lyophilization methods and characterized by nuclear magnetic resonance, Fourier-transformed infrared spectroscopy, X-ray diffraction, differential scanning calorimetry, and scanning electron microscopy techniques. In vivo assays compared CAP and CAP/CD complex administration $\left(0.5 \mathrm{mg} \mathrm{kg}^{-1}\right.$ or $\left.0.09 \mathrm{mg} \mathrm{kg}^{-1}, \mathrm{n}=4-7\right)$ to evaluate the ACE inhibition by continuous infusion of angiotensin I ( $30 \mathrm{ng} 50 \mu \mathrm{L}^{-1} \mathrm{~min}^{-1}$ ) in conscious Wistar rats. The physicochemical analysis demonstrated complete amorphization and complexation between CAP and CDs, indicating the substitution of water molecules inside the CD cavity with CAP. During the infusion of angiotensin I, the administration of all CAP/ $\mathrm{CD}$ complexes induced a reduction in mean arterial pressure similar to that observed upon CAP administration. The nanoparticles obtained by the kneading method (CAP/ $\alpha-C D: K M)$ showed a potent and long-lasting inhibitory activity ( $\sim 22$ hours) on the angiotensin I pressor effect. The results suggest that the inclusion complex of CAP and $\alpha-C D$ can function as a novel antihypertensive formulation that may improve therapeutic use of CAP by reducing its oral dose administration to once per day, thus providing better quality of life for almost $25 \%$ of the world's population who suffer from hypertension.

Keywords: captopril, cyclodextrin nanoparticles, sustained release

\section{Introduction}

Captopril (CAP) (Figure 1) is an angiotensin I-converting enzyme inhibitor ${ }^{1}$ that has been widely used for the treatment of hypertension and congestive heart failure. This drug acts orally and the dosage used for the treatment of these heart diseases ranges from $50 \mathrm{mg}$ to $150 \mathrm{mg}$ per day. With a single oral dose its maximum hemodynamic effect is observed after 45-90 minutes. ${ }^{1}$ The drug is also freely water soluble, has an elimination half-life of 1.7 hours, and is stable at $\mathrm{pH} 1.2$. As the $\mathrm{pH}$ increases, CAP becomes unstable and undergoes degradation. ${ }^{2,3}$ CAP has been a drug of choice in hypertension management; however, its antihypertensive action is effective for 6-8 hours, which is why three to four CAP administrations are required for successful medication. Therefore, development of a controlled delivery system for CAP would bring many advantages for hypertension patients, who compose almost 


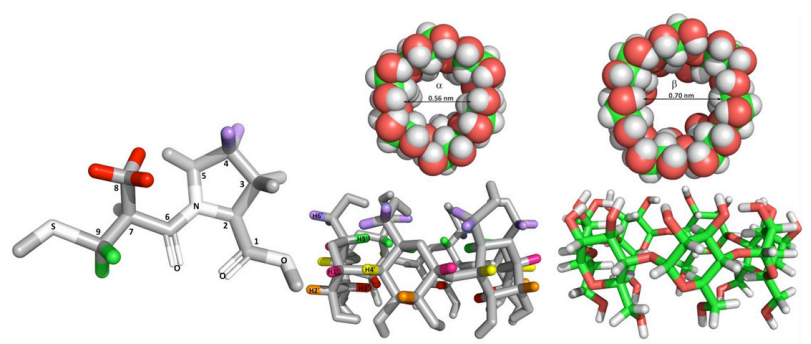

Figure I Captopril (CAP) ((2S)-I-[(2S)-2-methyl-3-sulfanylpropanoyl]-pyrrolidine2 -carboxylic acid) (left) and $\alpha$ - and $\beta$-cyclodextrins (CD) (middle and right) with indication of the captopril and cyclodextrin hydrogens. The CAP and $\alpha-C D$ hydrogens are colored purple, red, or green, due to observed interactions as indicated in nuclear magnetic resonance section.

$25 \%$ of the world's population. ${ }^{4,5}$ Development of oral controlled-release formulations for CAP is very difficult due to both in vivo and in vitro instability. The drug also undergoes dose dumping and burst phenomena (being freely water soluble) when formulated as controlled- or sustainedrelease formulations. ${ }^{6}$

Natural and semisynthetic cyclodextrins (CDs) have been extensively studied as host molecules, as they improve certain properties of drugs, such as solubility, stability, and bioavailability. ${ }^{7}$ These saccharides are suitable drug delivery systems because of their ability to greatly modify physicochemical properties and/or biological properties of guest molecules through labile interactions in the host/guest inclusion complexes formed. As was recently divulged by some of the authors of the present work, auraptene and 4'-geranylloxyferulic acid in inclusion complexes with $\beta-C D$ exhibit very effective results in inhibiting colon cancer. ${ }^{8}$ The inclusion of the active principles in the cage of $\beta-\mathrm{CD}^{9,10}$ protected drugs from absorption in the stomach and the upper portion of the lower intestine and enabled the degradation of the saccharide portion in the large bowel by intestinal microflora, thereby ensuring specific drug delivery with the maximum drug bioavailability. Although investigation into drug inclusion is one of the most extensively researched fields, and complexation and self-assembly of CDs and lipophilic drugs has been investigated for years, ${ }^{11-13}$ interactions between CDs and hydrophilic drugs have scarcely been reported. ${ }^{14-16}$ Such an interaction could result in a retarding effect of the associated hydrophilic drug. Therefore, one of the goals of the present work was to investigate whether a hydrophilic drug such as CAP could form associations or even complexes with CDs so as to obtain a potential antihypertensive formulation that may improve the therapeutic use of CAP.

Ikeda et a $1{ }^{17}$ reported on controlled CAP release by combining hydrophilic and hydrophobic CDs and derivatives in aqueous solutions in self-assembled complexes. Their results suggested that a combination of HP- and TB- $\beta$-CD with CAP could control the CAP release by adjusting the molar ratio between the inclusion complex components. In an article published in 2002, Ikeda et $\mathrm{al}^{18}$ also showed inclusion complex formation between $\alpha-, \beta$-, and HP- $\beta$-CDs as hosts, and CAP in aqueous solutions, analyzed principally by ${ }^{1} \mathrm{H}$ and ${ }^{13} \mathrm{C}$ nuclear magnetic resonance (NMR) spectroscopy. ${ }^{18}$

Herein, solid inclusion complex formation between CAP and three CDs ( $\alpha-, \beta$-, and HP- $\beta-C D s)$ is reported, and to assure that complexation between hydrophilic molecules and CDs is possible, four types of nanoparticles were obtained: kneaded, lyophilized, freeze-dried, and spray-dried. Fifteen inclusion complexes were then analyzed by applying classical methods, such as NMR, Fourier-transformed infrared (FTIR), differential scanning calorimetry (DSC), X-ray diffraction (XRD), and scanning electron microscopy (SEM).

Because a focus of our work was the sustained release of CAP, in vivo tests were executed with seven of the formulations and compared with CAP. The increase of the duration and magnitude of hypotensor CAP effects in the control of blood pressure in spontaneously hypertensive rats ${ }^{19}$ was observed. Therefore, nanoparticles of CAP and CD represent possible sustained-release devices that increase the duration and magnitude of CAP antihypertension effects.

\section{Experimental section Reagents}

CAP was purchased from Grupo Castro Marques (União Química Farmacêutica/Biolab Sanus, Lote 0500012197, Sao Paulo, Brazil) and from FURP (Lote RR379435/1, Sao Paulo, Brazil). $\alpha-C D$ and $\beta-C D$ were purchased from ISP Technologies, Inc (Waterford, MI), and 2-hydroxipropyl$\beta-C D$ (Kleptose/HP- $\beta-C D$ ) was purchased from Roquette (Lestrem, France).

\section{Inclusion compound preparation methods}

All inclusion compounds were prepared by kneading method $(\mathrm{KM})$, vacuum evaporation (VE), freeze-drying (FD), or spray-drying (SD) using 1:1 molar ratios between CAP and the corresponding CD. Physical mixtures (PM) were prepared by homogeneous blending of weighted CAP and CDs ( $\alpha-C D$, $\beta-C D$, and $\mathrm{HP}-\beta-\mathrm{CD})$ in a mortar.

\section{Kneading method (KM)}

CAP (217 mg) and $\alpha$-CD (972 mg), $\beta$-CD (1135 mg), or HP- $\beta$-CD (1413 mg), in molar ratios of $1: 1$, were accurately weighed and transferred to a mortar, triturated with a small 
amount of water, and kneaded thoroughly for approximately 50 minutes. During this process, an appropriate volume of water was added in order to maintain a suitable consistency and to avoid CAP degradation.

\section{Vacuum evaporation (VE)}

CAP-ethanol solutions of $500 \mathrm{mg} 280 \mathrm{~mL}^{-1}$ were mixed with $\beta$-CD aqueous solutions (2599 mg $420 \mathrm{~mL}^{-1}$ ). The solutions were mixed for 20 minutes by sonication until clear solutions were obtained. Then, the ethanol was evaporated under vacuum for 40 minutes and the products were dried at $37^{\circ} \mathrm{C}$ for 48 hours. The two other $\mathrm{CAP} / \mathrm{CD}$ formulations were obtained by the same protocol.

\section{Freeze-drying (FD)}

An appropriate amount of CD was dissolved in water. After that, CAP was added to this solution under stirring, with 1:1 stoichiometry. The suspension was stirred for 24-48 hours. The resultant clear solutions were frozen by immersion in an ethanol bath at $-50^{\circ} \mathrm{C}$ (Freezone model 79490; Shell Freezer, Labconco, Kansas City, MO) and then the frozen solutions were lyophilized in a freeze-dryer (ModulyoD-115; Thermo Fisher Scientific, Inc, Waltham, MA) for 72 hours.

\section{Spray-drying (SD)}

For this purpose, the hydroalcoholic solutions were prepared and spray-dried. The suspensions of CAP and $\alpha$-CD (972 mg), $\beta$-CD (1135 mg), or HP- $\beta$-CD (1413 mg) were prepared in a molar ratio of $1: 1$ and in ethanol:water $(1: 3, \mathrm{v} / \mathrm{v})$. These were mixed and stirred for 24-48 hours. The $\mathrm{pH}$ values of the solutions were adjusted during this process to avoid possible CAP degradation. Solutions were subsequently spray-dried in a mini Spray Dryer (B-290; Büchi, Flawil, Switzerland) with a two-component nozzle and concurrent flow. The drying conditions were as follows: flow rate, $10 \mathrm{~mL} \mathrm{~s}^{-1}$; inlet temperature of the drying chamber $\sim 130^{\circ} \mathrm{C}$; outlet temperature, $69^{\circ} \mathrm{C}$; and airflow rate, $400 \mathrm{~L} \mathrm{~h}^{-1}$. The residual water content of each spray-dried product was determined by loss of weight, and each analysis was repeated three times.

Fifteen samples were obtained (each CD with CAP in five different nanoparticle preparations): 1) $\mathrm{CAP} / \beta-\mathrm{CD}: \mathrm{PM} ; 2)$ $\mathrm{CAP} / \beta-\mathrm{CD}: \mathrm{KM}$; 3) CAP/ $\beta-\mathrm{CD}: \mathrm{VE}$; 4) CAP/ $\beta-\mathrm{CD}: \mathrm{FD}$; 5) CAP/ $\beta-\mathrm{CD}: \mathrm{SD}$; 6$) \mathrm{CAP} / \alpha-\mathrm{CD}: \mathrm{PM}$; 7) CAP $/ \alpha-\mathrm{CD}: \mathrm{KM}$; 8$) \mathrm{CAP} / \alpha-$ $\mathrm{CD}: \mathrm{VE}$; 9) CAP/ $\alpha-\mathrm{CD}: \mathrm{FD}$; 10) CAP/ $\alpha-\mathrm{CD}: \mathrm{SD}$; 11) $\mathrm{CAP} /$

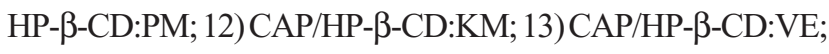
14) CAP/HP- $\beta-C D: F D$; and 15) CAP/HP- $\beta-C D: S D$. Seven of these samples were investigated more thoroughly.

\section{NMR spectroscopy}

The CAP/CD nanoparticle samples were prepared in $\mathrm{D}_{2} \mathrm{O}$ (99.9\%) or in DMSO-d6, purchased from Cambridge Isotope Laboratories (Andover, MA), at concentrations of approximately $15 \mathrm{mg} \mathrm{mL}^{-1}$. All experiments were performed at $298 \mathrm{~K}$ in an INOVA-500 spectrometer (Varian, Palo Alto, CA). The ${ }^{1} \mathrm{H}$ NMR experiments ( $\mathrm{D}_{2} \mathrm{O}$ samples) were acquired with $32 \mathrm{k}$ data points applying a $90^{\circ}$ excitation pulse with duration of $3.15 \mu \mathrm{s}$, spectral width of $4.5 \mathrm{kHz}$, acquisition time of 4 seconds, and relaxation delay of 1 second, using a $5 \mathrm{~mm}$ triple resonance probe. The diffusion ordered spectroscopy (DOSY) experiments were carried out through the gradient compensated stimulated echo spin lock with convection compensation (DgcsteSL_cc) high-resolution DOSY sequence. Twenty-five different amplitudes of the gradient pulses ranging from $6.85 \times 10^{-4} \mathrm{~T} \mathrm{~cm}^{-1}$ to $4.22 \times 10^{-3} \mathrm{~T} \mathrm{~cm}^{-1}$ were applied, achieving an approximately $90 \%-95 \%$ decrease in the resonance intensity with the highest gradient amplitudes. The baselines of all spectra were corrected and then the DOSY macro program (Varian) was used, involving the determination of the peak heights of all signals above a pre-established threshold. The curves of each peak were fitted with corresponding exponential decay. The DOSY data represent pseudo two-dimensional spectra having ${ }^{1} \mathrm{H}-\mathrm{NMR}$ chemical shifts along one axis and the calculated diffusion coefficients $\left(10^{-10} \mathrm{~m}^{2} \mathrm{~s}^{-1}\right)$ along the other. In the rotating-frame Overhauser enhancement spectroscopy (ROESY) experiments, selective $\left(180^{\circ}\right)$ and nonselective $\left(90^{\circ}\right)$ pulses with a mixing time of $400 \mathrm{~ms}$ and $300 \mathrm{~ms}$ during the spin lock were applied, and the relaxation delay was 1.5 seconds. A modulator generated the selective pulses and automatically attenuated the power and duration of the pulse. ${ }^{13} \mathrm{C}$ NMR and heteronuclear single-quantum correlation (HSQC) (DMSO-d6 samples) were carried in $5 \mathrm{~mm}$ broadband or triple resonance probes, respectively. ${ }^{13} \mathrm{C}$ NMR experiments were acquired with $32 \mathrm{k}$ data points, spectral width of $3.0 \mathrm{kHz}$, and relaxation delays of 1.5 seconds at $125.709 \mathrm{MHz}$. The $\left\{{ }^{13} \mathrm{C}-{ }^{1} \mathrm{H}\right\}$ HSQC spectra were obtained with data size and spectral widths of 128 $(\mathrm{t} 1) \times 1024(\mathrm{t} 2)$ and $22800 \mathrm{~Hz}\left(\omega 1,{ }^{13} \mathrm{C}\right) \times 4000 \mathrm{~Hz}(\omega 2$, $\left.{ }^{1} \mathrm{H}\right)$, respectively, and relaxation delays of 1.5 seconds.

\section{FTIR spectroscopy}

Samples of the solid dispersions and physical mixtures of CAP and $\alpha-, \beta$-, and HP- $\beta-C D$ in molar ratios of $1: 1$ were mixed with $\mathrm{KBr}$ and pressed to small tablets mounted in the infrared beam (MB 100 FTIR spectrometer; ABB Bomem, Inc, Zurich, Switzerland). 


\section{DSC}

Measurements of the pure materials (CAP and CD) and the binary systems were carried out using a DSC-STAR system (Mettler Toledo Inc, Columbus, $\mathrm{OH}$ ). The thermal behavior was studied by heating the samples in a sealed aluminum pan from $25^{\circ} \mathrm{C}$ to $600^{\circ} \mathrm{C}$ at a rate of $10^{\circ} \mathrm{C} \mathrm{min}^{-1}$ under a nitrogen flow of $40-50 \mathrm{~mL} \mathrm{~min}^{-1}$.

\section{XRD studies}

The powder XRD patterns of the samples were recorded using a Siemens D 5000-XRD (Siemens Electronical Equipment, Toronto, $\mathrm{ON}$ ) under the following conditions: target, $\mathrm{Cu}$; filter, $\mathrm{Ni}$; voltage, $40 \mathrm{kV}$; current, $30 \mathrm{~mA}$; scanning speed $2^{\circ} \mathrm{C} \mathrm{min}^{-1}$; chart speed, $40 \mathrm{~mm} \mathrm{~min}^{-1}$; and count range, 1000 counts $\mathrm{s}^{-1}$. The detector was a proportional counter with 1.7 $\mathrm{kV}$ detector.

\section{SEM studies}

The morphological features of CAP, $\alpha$ - and $\beta$-CDs, and the CAP/CD systems (physical mixture, kneaded, vacuumevaporated, freeze-dried, and spray-dried) were studied by SEM using JSM-5400 equipment, employing $20 \mathrm{kV}$ of tension after sputtering the samples with a thin layer of gold to make the surfaces conductive.

\section{In vivo assays}

\section{Animals}

Experiments were carried out in male Wistar rats (280$320 \mathrm{~g}$ ) bred at the animal facility of the Biological Science Institute (CEBIO, Federal University of Minas Gerais, Belo Horizonte, Brazil). The animals had free access to food and water and were submitted to a light-dark cycle (12 hours each) before experiments. The experimental protocol was performed in accordance with the guidelines for the human use of laboratory animals of the cited institute and approved by local authorities.

\section{Blood pressure recording in rats}

\section{Arterial pressure measurements}

The cardiovascular parameters pulse arterial pressure (PAP), mean arterial pressure (MAP), and heart rate (HR) were monitored by a solid-state strain gauge transducer connected to a computer through a data acquisition system (MP 100; BIOPAC Systems, Inc, Goleta, CA). The PAP, MAP, and HR were monitored jointly during experiments in different monitor channels and recorded in the computer hard disk for posterior analysis.

\section{Inhibition of the pressor effect of angiotensin I on BP in conscious Wistar rats}

Twenty hours before the experiment, under tribromoethanol anesthesia (2.5\% $1.0 \mathrm{~mL} 100 \mathrm{~g}^{-1}$ of body weight), polyethylene catheters (PE-10 connected to PE-50) were introduced into abdominal aorta through the femoral artery and vein for recording cardiovascular parameters and intravenous injections, respectively. After recovery from anesthesia, the rats were kept in individual cages with free access to water and food until the end of the experiments. Before drug administration, the cardiovascular parameters were monitored for 10-15 minutes. Next, a continuous intravenous infusion of angiotensin I (30 ng $50 \mu \mathrm{L}^{-1} \mathrm{~min}^{-1}$ ) was performed using an infusion pump (Pump 11; Harvard Apparatus, Holliston, MA). After stabilization of cardiovascular parameters during angiotensin I infusion, CAP, CAP/CD complexes, or vehicle (water) were given by gavage $\left(0.09 \mathrm{mg} \mathrm{kg}^{-1}\right.$ and $0.5 \mathrm{mg} \mathrm{kg}{ }^{-1}$ of CAP in each formulation) in a total volume of $0.3 \mathrm{~mL}$. Uncomplexed CAP was used as positive control. The cardiovascular parameters were monitored continuously over 2 hours after drug administration. MAP and HR values were computed at regular intervals ( 3 minutes, 15 minutes, 30 minutes, 45 minutes, 60 minutes, 75 minutes, 90 minutes, 105 minutes, and 120 minutes $)(n=4-7)$. Also, PAP, MAP, and HR parameters were monitored after 20-24 hours of administration.

\section{Statistical analysis}

Comparisons were made by Student's unpaired $t$-test or twoway analysis of variance with Bonferroni post hoc test when appropriate. GraphPad Prism 5.0 software (GraphPad Software, Inc, La Jolla, CA) was used in all statistical analysis. The criterion for statistical significance was set at $P<0.05$.

\section{Results and discussion NMR}

We initiated our investigation by analyzing the complexationinduced chemical shifts $(\mathrm{CICSs})^{20}$ in the complexes. The hydrogen atoms of guest molecules included in the CD nanocavities, as well as $\mathrm{CD}$ hydrogens, can undergo changes in chemical shifts due to the changes in their local environment. As has been frequently observed, ${ }^{21,22}$ the signals of $\mathrm{H} 3$ ' and H5' hydrogens on the inner surface of the $\mathrm{CD}$ (Figure 1) are shifted significantly upfield, whereas H1', H2', and H4' hydrogens on the outer surface experience minimal changes. 


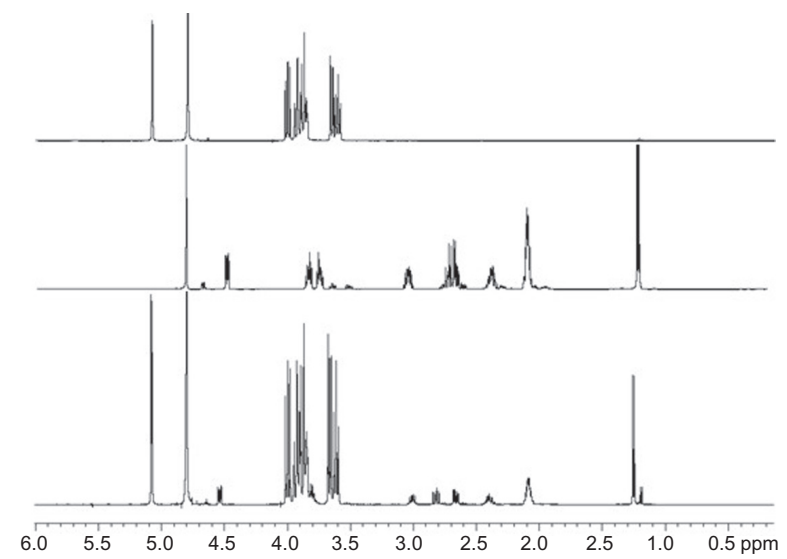

Figure 2 ' $\mathrm{H}$ nuclear magnetic resonance spectra showing $\alpha$-cyclodextrin $(\alpha-C D$,

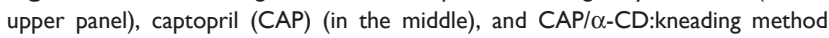
(lower panel) in the $0.1-6.0 \mathrm{ppm}$ range. A residual water signal is present at $4.8 \mathrm{ppm}$ and evident in all samples.

Thus, the chemical displacement of the CDs induced by the presence of the guest and the CICSs of CAP are the first evidence of CAP inclusion in CDs (Figure 2).

The hydrogen atoms of CAP and the CDs were denominated in accordance with Figure 1, and the best results for formulations are summarized in Tables 1 and 2.

The chemical shifts of H6' hydrogens (CDs) are not shown in Table 1 because of the overlap with the signals corresponding to H5', which are also not shown. As is already described in the literature, ${ }^{23}$ when $\left|\Delta \delta \mathrm{H} 3^{\prime}\right|>\left|\Delta \delta \mathrm{H} 5^{\prime}\right|$, the guest inclusion inside the CD cavity is partial, and when $\left|\Delta \delta \mathrm{H} 3^{\prime}\right| \leq\left|\Delta \delta \mathrm{H} 5^{\prime}\right|$, the guest is included more deeply into the cavity. The results (Table 1) showed partial inclusion of $\mathrm{CAP}$ in $\beta$-CD nanoparticles and total inclusion of CAP in $\alpha-\mathrm{CD}$ and HP- $\beta$-CD.

Unfortunately, the H5 CAP hydrogens (proline ring) of CAP could not be quantitatively analyzed due to overlapping with the NMR signals from the CD.
Table 2 shows the chemical shifts of the CAP hydrogens and their CICSs due to complexation with CDs. The CICS of CAP complexed with $\alpha-C D$ are higher than those measured in $\beta-C D$ and HP- $\beta-C D$ complexes, maybe because of stronger guest interactions with the $\alpha$-CD cavity. In the case of the $\alpha$-CD complexes, higher CICSs were observed for the propyl thioalcohol hydrogen (H9a) when compared with the proline hydrogens ( $\mathrm{H} 2$ and $\mathrm{H} 3$ ). The CICSs of the $\beta-\mathrm{CD}$ and $\beta$-HP-CD follow a slightly different tendency. The larger ones were observed for hydrogens in the center of the CAP molecule (H7 and H8), whereas the changes in CICSs of the terminal hydrogens (H9) were small. These results suggest that the terminal alkyl unit (thiol moiety) of the CAP is included in the CD cavity. The CICS data confirmed our expectations that $\mathrm{CAP}$ in an inclusion complex with $\alpha-\mathrm{CD}$ in the formulation denominated $\mathrm{CAP} / \alpha-\mathrm{CD}: \mathrm{KM}$ presents higher values, due to having stronger intramolecular interactions with the host molecule, as well as CAP insertion with the thiol moiety in the $\alpha$-CD cavity, which is also observed in FTIR analysis. Other CAP inclusion complexes with $\beta-C D$ and HP- $\beta-C D$ collaborated with FTIR data and indicated more probable guest molecule inclusion by the proline moiety in the corresponding $\mathrm{CD}$ cavities.

\section{ROESY NMR}

The ROESY experiments were carried out in order to gain insights into the inclusion mode of the complexes in aqueous solution. The ROESY spectrum, shown in Figure 3, provided information about which $\alpha$-CD hydrogen has an intermolecular correlation with the CAP hydrogens. There are ROE crosspeaks between the H-4 and the $\alpha-\mathrm{CD}$ H- 6 ' hydrogen resonances (in purple in Figure 3), as well as H-8 and H-3' (in red in Figure 3). Additionally, we can find another ROE crosspeak between the H-9 and H-5' hydrogen resonances

Table I 'H NMR chemical shifts of cyclodextrin (CD) hydrogens in $D_{2} \mathrm{O}$ and their CICS in the respective complexes, for $\alpha-C D$ ( $\alpha$-cyclodextrin) and its formulation with Captopril (CAP/ $\alpha-C D: K M) ; \beta-C D$ ( $\beta$-cyclodextrin) and its formulation (CAP/ $\beta$-CD:SD); HP$\beta-C D$ (hydroxypropyl- $\beta$-cyclodextrin) and its formulation (CAP/HP- $\beta-C D: S D)$

\begin{tabular}{|c|c|c|c|c|c|c|}
\hline \multirow[t]{2}{*}{$\mathbf{H}$} & $\alpha-C D$ & CAP/ $\alpha-C D: K M$ & $\beta-C D$ & CAP/ $\beta-C D: S D$ & $H P-\beta-C D$ & CAP/HP- $\beta-C D: S D$ \\
\hline & $\delta$ & $\delta(\Delta \delta)$ & $\delta$ & $\delta(\Delta \delta)$ & $\delta$ & $\delta(\Delta \delta)$ \\
\hline $\mathrm{I}^{\prime}$ & 5.08 & $5.08(0)$ & 5.10 & $5.09(-0.01)$ & 5.26 & $5.25(-0.01)$ \\
\hline $2^{\prime}$ & 3.66 & $3.67(0.01)$ & 3.68 & $3.67(-0.01)$ & 3.60 & $3.65(0.05)$ \\
\hline $3^{\prime}$ & 4.01 & $4.00(-0.01)$ & 3.99 & $3.96(-0.03)$ & 5.10 & $5.10(0)$ \\
\hline $4^{\prime}$ & 3.61 & $3.61(0)$ & 3.61 & $3.61(0)$ & 1.18 & $1.17(-0.01)$ \\
\hline $5^{\prime}$ & 3.90 & $3.88(-0.02)$ & 3.90 & $3.88(-0.02)$ & 3.94 & $3.91(-0.03)$ \\
\hline
\end{tabular}

Note: $\Delta \delta=\delta_{\text {complexed }}-\delta_{\text {tree }}$ 
Table 2 'H NMR chemical shifts of Captopril hydrogens in $\mathrm{D}_{2} \mathrm{O}$ and their CICS in the complexes with $\alpha, \beta$ and HP cyclodextrins respectively, where $\Delta \delta=\delta_{\text {complexed }}-\delta_{\text {free }}$

\begin{tabular}{|c|c|c|c|c|}
\hline & Captopril & $\begin{array}{l}\text { CAP/ } \alpha-C D: \\
K M\end{array}$ & $\begin{array}{l}\text { CAP/ } \beta-C D: \\
\text { SD }\end{array}$ & $\begin{array}{l}\text { CAP/HP- } \beta-C D: \\
\text { SD }\end{array}$ \\
\hline & $\delta$ & $\delta(\Delta \delta)$ & $\delta(\Delta \delta)$ & $\delta(\Delta \delta)$ \\
\hline 2 & 4.48 & $4.54(0.06)$ & $4.50(0.02)$ & $4.49(0.01)$ \\
\hline 5 & 3.82 & - & - & - \\
\hline 5 & 3.73 & - & - & - \\
\hline 7 & 3.02 & $3.01(-0.01)$ & $2.95(-0.07)$ & $2.98(-0.04)$ \\
\hline $9 a$ & 2.70 & $2.82(0.12)$ & $2.72(0.02)$ & $2.72(0.02)$ \\
\hline $9 b$ & 2.63 & $2.66(0.03)$ & $2.63(0)$ & $2.64(0.01)$ \\
\hline 3 & 2.35 & $2.39(0.04)$ & $2.35(0)$ & $2.34(-0.01)$ \\
\hline 4 & 2.06 & $2.08(0.02)$ & $2.10(0.04)$ & $2.09(0.03)$ \\
\hline 8 & 1.17 & I. $25(0.08)$ & $1.22(0.05)$ & I.2I (0.04) \\
\hline
\end{tabular}

(circled in green in Figure 3 ) that confirms the inclusion mode for the complex CAP/ $\alpha-C D: K M$ in aqueous solution obtained by CICS analysis.

\section{DOSY NMR}

The DOSY NMR experiments were important to confirm the complexation of CAP with $\mathrm{CD}$, and the diffusion coefficients also provided valuable information on molecular organization and phase structures. These experiments allowed distinguishing complexes by observed differences in diffusion coefficients. Furthermore, we have investigated the self-assemblies between host and guest molecules by mixing solutions of CAP and the respective $\mathrm{CD}\left(\mathrm{D}_{2} \mathrm{O}\right)$ in the same proportion as used in the preparation of nanoparticles (1:1 molar ratios). As explained in the experimental section, after properly preprocessing data, the diffusion coefficients were obtained automatically and the diffusion coefficient values were calculated as the averages of all the listed coefficients. The results for the best IC are shown in Table 3.

The guest population involved in the complexation was calculated from the observed diffusion coefficient of each component in the complexed and free forms, applying a well-established methodology. ${ }^{24,25}$ The degree of complexation between CAP and $\alpha-\mathrm{CD}$ is evidently higher compared with other samples and occurred even in the selfassembled sample (Table 3, mixture of $\alpha-C D+C A P, 23.6 \%$ ); therefore, it was proven that CAP is completely included in the $\alpha-C D$ cavity, as already seen in the ${ }^{1} \mathrm{H}$ NMR data. A somewhat higher degree of complexation was measured

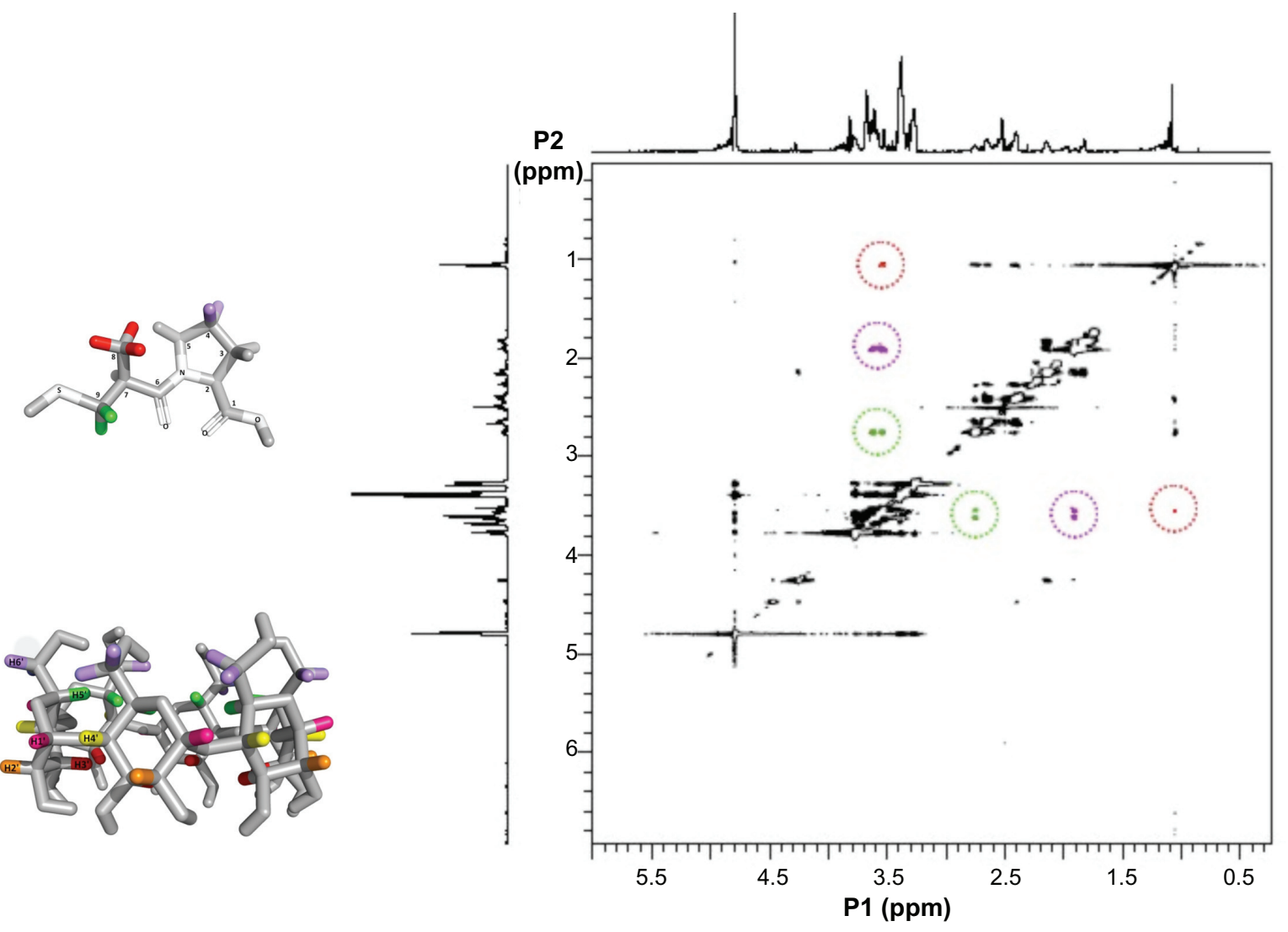

Figure 3 Rotating-frame Overhauser enhancement spectroscopy nuclear magnetic resonance map $(0.3-6.0$ ppm range) with interactions between hydrogen atoms in the formulation captopril (CAP)/ $\alpha$-cyclodextrin (CD):kneading method. CAP H-9 and $\alpha-C D \mathrm{H}-5$ ' (in green), $\mathrm{H}-4$ and $\mathrm{H}-6$ ' (in purple), and $\mathrm{H}-8$ and $\mathrm{H}-3$ ' (in red). Residual water signal is present at $4.8 \mathrm{ppm}$. The $\alpha-C D$ (lower panel) and CAP (upper panel) are shown on the left side. 
Table 3 Diffusion coefficients (D) obtained in DOSY-NMR experiments for Captopril (free and bonded) and cyclodextrins ( $\alpha, \beta$ and $\mathrm{HP}-\beta-C D$ ) with corresponding percent of captopril complexed population ( $\mathrm{P}_{\text {complexed }}$ in \%)

\begin{tabular}{llll}
\hline Solution & $\mathbf{D}_{\text {captopril }} / 1 \mathbf{0}^{-10} \mathbf{m}^{2} \mathbf{s}^{-1}$ & $\mathbf{D}_{\mathrm{CD}} / 1 \mathbf{0}^{-10} \mathbf{m}^{2} \mathbf{s}^{-1}$ & $\mathbf{P}_{\text {complexed }}(\%)$ \\
\hline free captopril & $4.26 \pm 0.02$ & - & - \\
free $\alpha-C D$ & - & $2.33 \pm 0.01$ & - \\
CAP/ $\alpha-C D: K M$ & $3.59 \pm 0.07$ & $2.30 \pm 0.01$ & 34.2 \\
Mixture $\alpha-C D+$ captopril & $3.78 \pm 0.05$ & $2.23 \pm 0.04$ & 23.6 \\
free $\beta-C D$ & - & $2.28 \pm 0.01$ & - \\
CAP/ $\beta-C D: S D$ & $3.6 \pm 0.1$ & $2.15 \pm 0.01$ & 31.3 \\
Mixture $\beta-C D+$ captopril & $4.17 \pm 0.04$ & $2.21 \pm 0.05$ & 4.4 \\
free HP- $\beta-C D$ & - & $1.95 \pm 0.02$ & - \\
CAP/HP- $\beta-C D: S D$ & $3.8 \pm 0.3$ & $1.95 \pm 0.04$ & 20.0 \\
Mixture HP- $\beta-C D+$ captopril & $4.29 \pm 0.08$ & $2.04 \pm 0.06$ & 1.4 \\
\hline
\end{tabular}

for $\mathrm{CAP} / \alpha-\mathrm{CD}: \mathrm{KM}$ formulation $(34.2 \%)$, as well as for $\mathrm{CAP} / \beta-\mathrm{CD}: \mathrm{SD}(31.3 \%)$.

NMR data enabled the pattern for supramolecular interactions to be established and to propose the model for a host-guest complex named CAP/ $\alpha-\mathrm{CD}: \mathrm{KM}$, as illustrated in Figure 4.

\section{${ }^{13} \mathrm{C}-\mathrm{NMR}$ and 2D NMR}

${ }^{13} \mathrm{C}$-NMR and HSQC experiments were executed to confirm the results obtained by the ${ }^{1} \mathrm{H}-\mathrm{NMR}$ and ROESY experiments and helped to better understand the supramolecular interactions between CAP and the $\mathrm{CD}$. The ${ }^{13} \mathrm{C}$ chemical shift displacements of $\alpha-\mathrm{CD}$ and CAP in the formulations follow the same tendency observed in the ${ }^{1} \mathrm{H}$ CICS, with greater displacements in $\mathrm{C} 7, \mathrm{C} 8$, and $\mathrm{C} 9$ of CAP. Furthermore, the $\left\{{ }^{13} \mathrm{C}-{ }^{1} \mathrm{H}\right\}$ HSQC experiment helped us to clear up doubts in guest-host interactions that showed that proline moiety is the most altered in complex with $\alpha-\mathrm{CD}$, and the $\mathrm{C} 7-\mathrm{H} 7, \mathrm{C} 8-\mathrm{H} 8$, and C9-H9 correlation signals suffered significant shifts in comparison with the HSQC map of CAP.
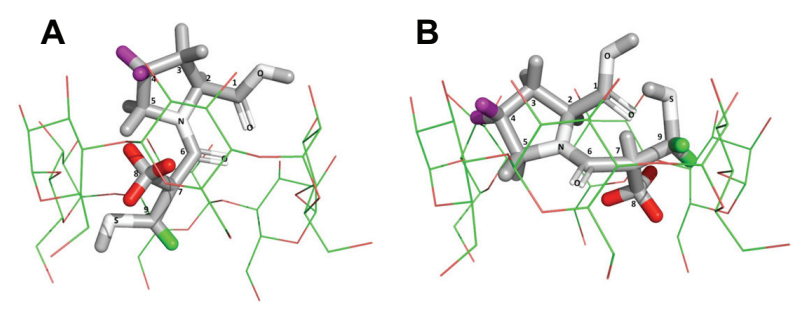

Figure 4 Proposed structure for captopril and $\alpha$-cyclodextrin $(C D)$ in the captopril (CAP)/ $\alpha-C D$ :kneading method inclusion complex. The CAP is completely included in the $\alpha-C D$ cavity; $\alpha-C D$ upper and broader cone side accommodates CAP whose thiol moiety is completely introduced into the cavity and is illustrated in two different perspectives $(\mathbf{A})$ and $(\mathbf{B})$. The hydrogen atoms in green $(\mathrm{H}-9)$, purple $(\mathrm{H}-4)$, and red $(\mathrm{H}-8)$ on the CAP molecule are the most altered by complexation, as measured in rotating-frame Overhauser enhancement spectroscopy nuclear magnetic resonance and seen by complexation-induced chemical shifts.

\section{FTIR spectroscopy}

All solids were analyzed by FTIR, but this technique was only effective in analyzing the binary systems obtained by spraydrying in the case of $\beta$-CD inclusion complexes, and by the kneading method in the case of $\alpha-\mathrm{CD}$ inclusion complexes. The general trend of spectra showed that CAP IR bands are masked by CD IR bands (data not shown). When analyzing the IR spectra of CAP/ $\beta-C D: S D$ and $C A P / \alpha-C D: K M$, it appeared that the CAP IR band attributed to axial strain S-H $\left(2565 \mathrm{~cm}^{-1}\right)$ disappeared when compared with the IR spectra of compounds obtained by other methods. Also, aliphatic C-H stretching and C-N IR bands in the $2800-3000 \mathrm{~cm}^{-1}$ region were missing. Therefore, the $\beta$ - and $\alpha-C D$ probably interacted with CAP thiol and proline moieties by completely accommodating the guest within the corresponding nanocavity. These inclusion complexes in both control and preclinical tests were the ones with the best performance in maintaining stable blood pressure upon angiotensin I infusion.

\section{DSC}

Data indicated that CAP has a thermal curve typical for a crystalline anhydrous substance with a sharp fusion endotherm at $103-108^{\circ} \mathrm{C}$, corresponding to the melting point of the drug. The DSC curve obtained for $\beta$-CD had a broad endothermic effect around $85-90^{\circ} \mathrm{C}$, associated to crystal water losses from $\mathrm{CD}^{26}$ When physical mixtures were analyzed by DSC (Figure 5), the CAP endothermic peak around $103-108^{\circ} \mathrm{C}$ was clearly distinguishable from additional peaks, due to the $\beta-\mathrm{CD}$ dehydration effect. These curves are, in fact, the superposition of the individual DSC components curves, ${ }^{27}$ showing the absence of interaction between the drug and $\mathrm{CD}$ in such systems.

It is known that when guest molecules are embedded in CD cavities or in the crystal lattice, their melting, boiling, or sublimation points generally shift to a different temperature or disappear within the temperature range where 

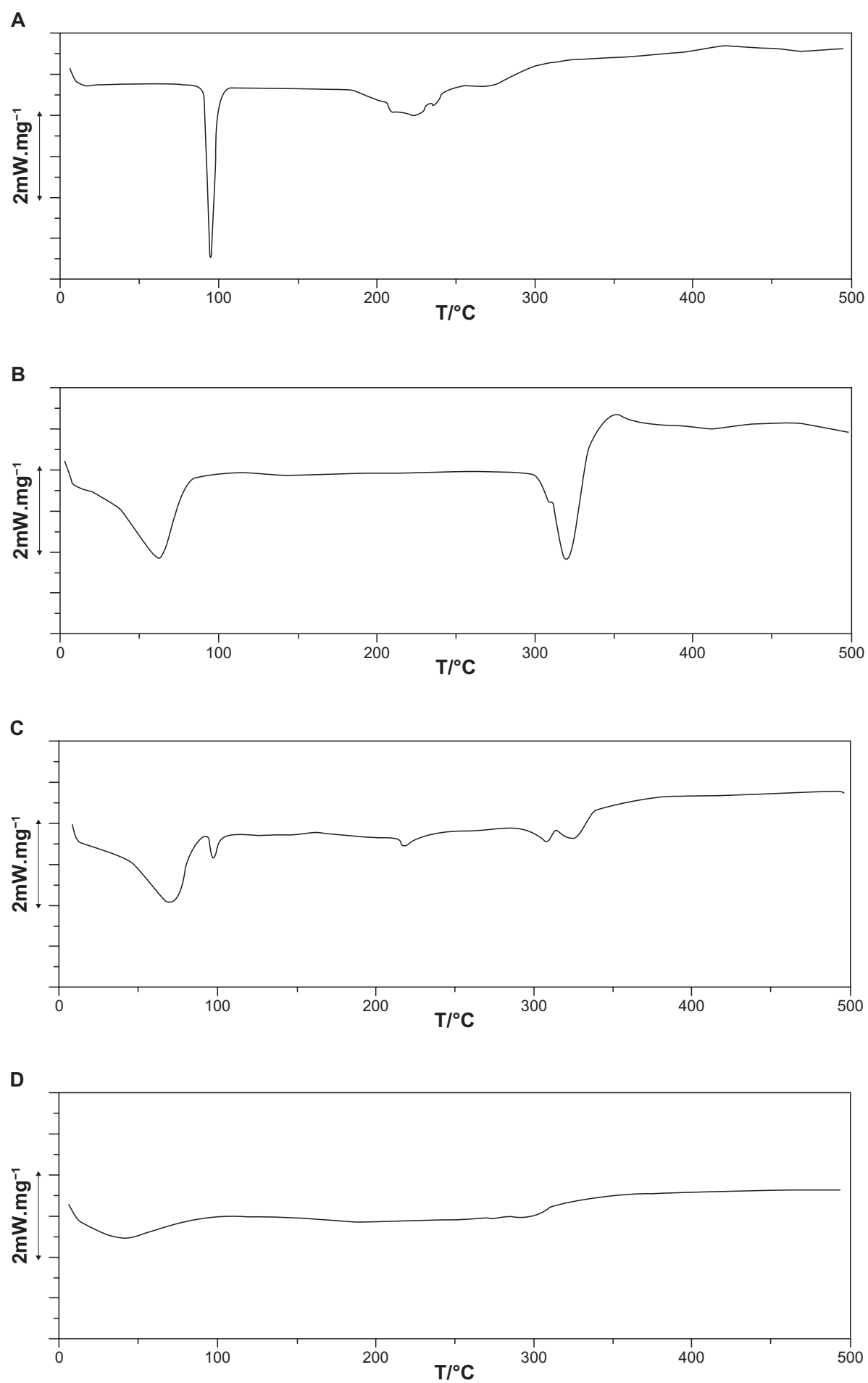

Figure 5 Differential scanning calorimetry thermograms of $\mathbf{A}$ ) captopril (CAP), B) $\beta$-cyclodextrin (CD), C) CAP/ $\beta$-CD:physical mixture, and D) CAP/ $\beta$-CD:spray-dried.

CD is decomposed. ${ }^{28}$ Therefore, the disappearance of the CAP melting point in the $\mathrm{CAP} / \alpha-\mathrm{CD}: \mathrm{SD}, \mathrm{CAP} / \alpha-\mathrm{CD}: \mathrm{KM}$, and $\mathrm{CAP} / \mathrm{HP}-\beta-\mathrm{CD}: \mathrm{SD}$ inclusion complexes suggests the formation of amorphous solid dispersion and/or inclusion complexes..$^{29}$ These results provide strong evidence that only four nanoparticles, CAP/ $\alpha-\mathrm{CD}: \mathrm{SD}, \mathrm{CAP} / \alpha-\mathrm{CD}: \mathrm{KM}, \mathrm{CAP} /$
HP- $\beta$-CD:SD, and CAP/ $\beta-C D: V E$, can be considered true inclusion complexes. ${ }^{30}$

\section{XRD studies}

The XRD patterns of $\mathrm{CAP} / \beta-\mathrm{CD}, \mathrm{CAP} / \alpha-\mathrm{CD}$, and $\mathrm{CAP} /$ HP- $\beta-C D$ systems are presented in Figure 6. CAP, $\alpha-C D$, 


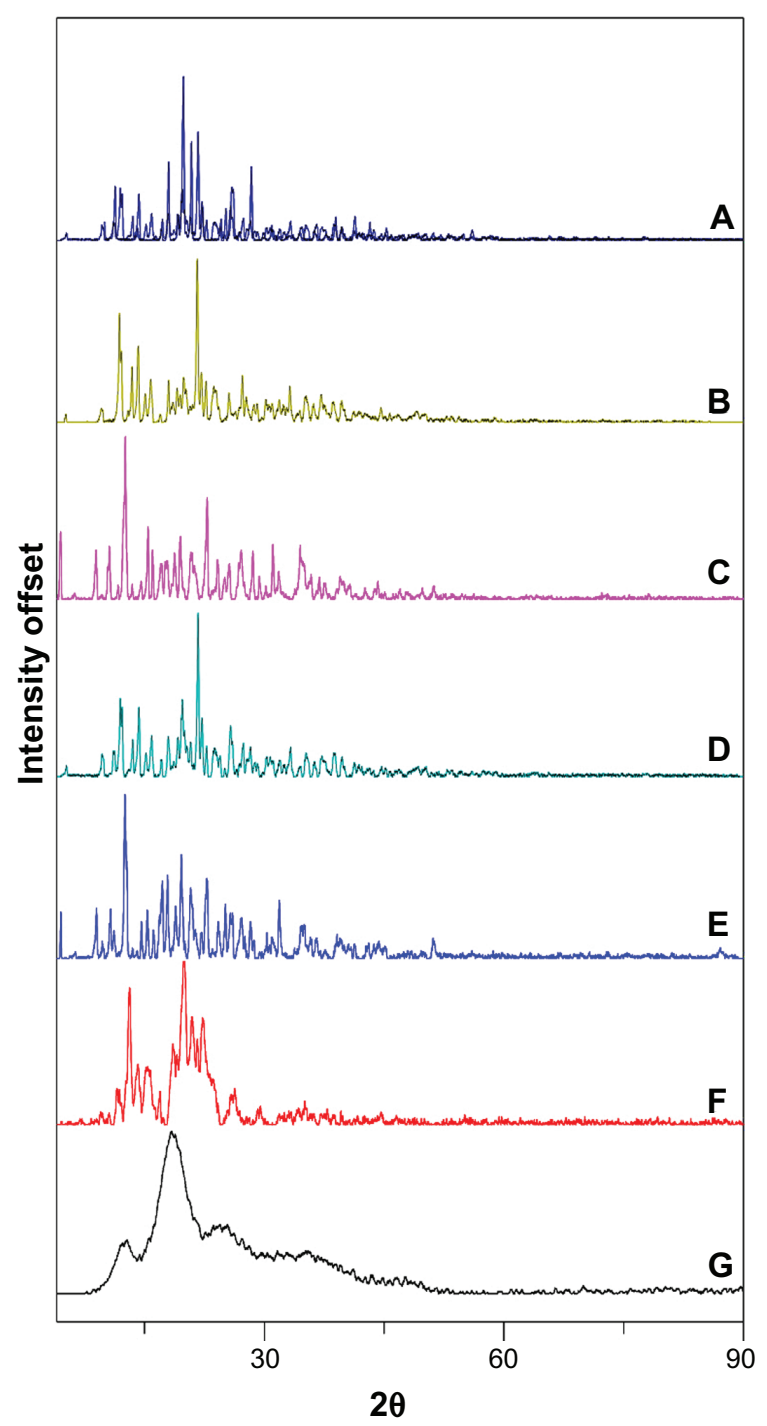

Figure 6 X-ray powder diffraction of A) captopril (CAP), B) $\alpha$-cyclodextrin (CD), C) $\beta-C D$, D) CAP/ $\alpha-C D$ :physical mixture, E) CAP/ $/ C D: P M, ~ F) ~ C A P / \alpha-$ $C D$ :kneading method, and $\mathbf{G )} C A P / \beta-C D$ :spray-dried.

and $\beta-C D$ exhibited intense peaks and crystalline structure (Figure $6 \mathrm{~A}-\mathrm{C}$ ). The XRD pattern of $\mathrm{CAP} / \beta-\mathrm{CD}: \mathrm{PM}$ (Figure 6E) is practically constituted from the superposition of the spectra corresponding to the individual components, providing evidence that an inclusion complex was not formed. The reduction in crystallinity was complete in the spray-dried powder (CAP/ $\beta$-CD:SD, Figure $6 \mathrm{G}$ ), showing a completely diffuse diffraction pattern, which revealed its amorphousness.

The absence of any peak in the HP- $\beta$-CD diffractograms revealed the amorphous nature of this compound (data not shown). The other HP- $\beta$-CD systems displayed diffuse diffraction patterns (identical to those of HP- $\beta-C D$ without drug peaks), indicating the entirely amorphous nature of $\mathrm{CAP}$ in these products. As for $\alpha-\mathrm{CD}$, the diffraction profile of the CAP/ $\alpha-C D: P M$ sample was found to be the simple superposition of XRD of each component (Figure 6D). The reduction in crystallinity was evident in the kneaded powder $(\mathrm{CAP} / \alpha-\mathrm{CD}: \mathrm{KM}$, Figure $6 \mathrm{~F}$ ), with the crystalline peaks of CAP emerging in the diffuse background. These results may be attributed to an interaction between CAP and $\alpha-C D$ and $\beta-C D$, in the kneaded and spray-dried products, suggesting the presence of a new solid phase with lower crystallinity than the drug, where a possible complexation of CAP inside the $\mathrm{CD}$ cavity was contemplated, corroborating the DSC observations.

\section{SEM studies}

Although the SEM technique is not suitable to prove the formation of an inclusion complex, it can confirm the existence of one or several components and supply information about particle size and shape. SEM studies revealed that CD crystallizes in polyhedral form. Pure CAP examined by SEM appeared as crystal particles with large dimensions, and its physical mixtures with $\alpha$ - and $\beta$-CD showed both crystalline components (Figures 7A and 7B).

Microphotographs of the samples prepared by kneading and spray-drying for $\alpha$ - and $\beta$-CD showed a strong reduction in the particle size (Figures 7C and 7D) due to the processing methods employed, which provoked a high degree of particle agglomeration, although the wetability of CAP increased. The vacuum-evaporated samples show clear differences in crystallization, with new crystalline products in CAP inclusion complexes with both CDs (data not shown).
A

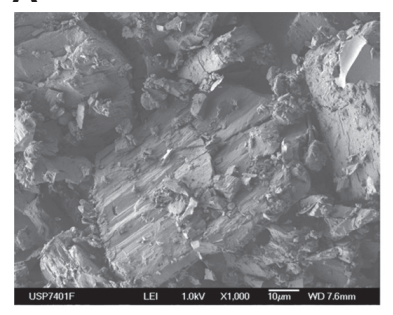

C

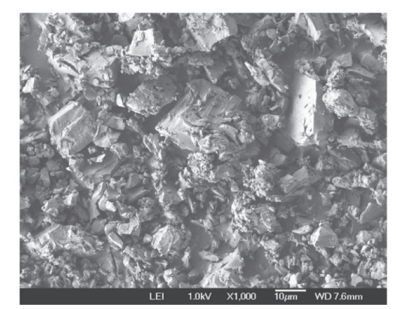

B

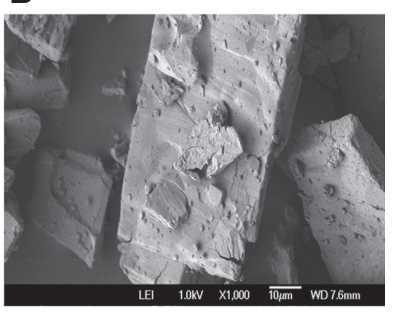

D

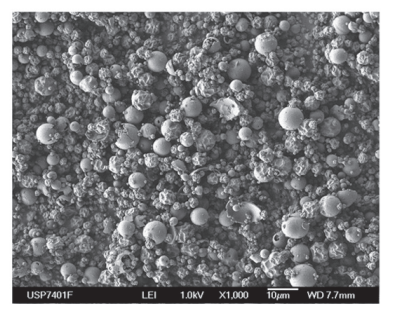

Figure 7 Scanning electron microscopy images of A) captopril (CAP)/ $\alpha$-cyclodextrin (CD):physical mixture, B) $C A P / \beta-C D$ :physical mixture, C) $C A P / \alpha-C D$ :kneading method, and (D) CAP/ $\beta-C D$ :spray-dried. 

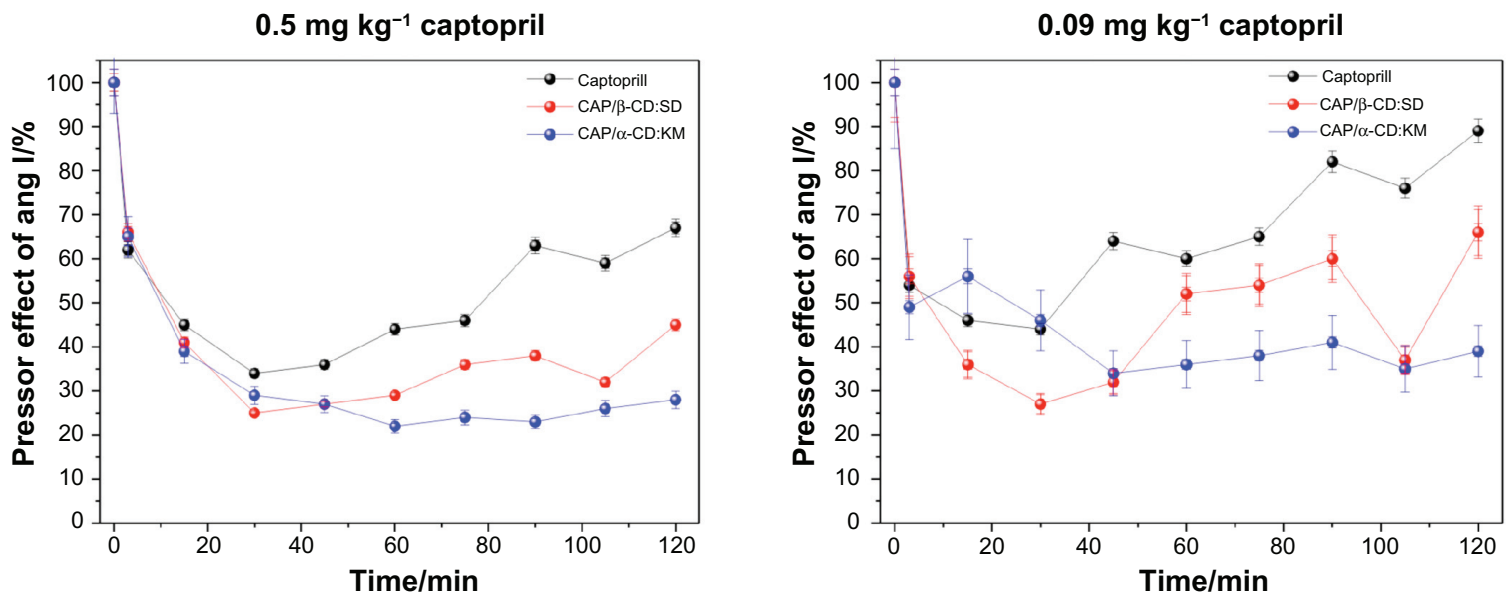

Figure 8 Reduction of the angiotensin I pressor response in conscious rats provoked with administration of two captopril (CAP) inclusion complexes at a dose of A) $0.5 \mathrm{mg} \mathrm{kg}^{-1}$ (CAP concentration in each inclusion complex) and B) $0.09 \mathrm{mg} \mathrm{kg}^{-1}$. Both graphics show CAP-free effects. Complexes of $\alpha$ - and $\beta$-cyclodextrin showed longlasting inhibitory effects when compared with CAP $(P<0.05)$.

\section{In vivo evaluation}

\section{Blood pressure recording in rats}

The results showed that all investigated inclusion complexes as well as CAP reduced the pressor response evoked by angiotensin I. Figure 8 shows the inhibitory effects of two CAP/CD complexes $\left(0.5 \mathrm{mg} \mathrm{kg}^{-1} \mathrm{CAP}\right.$ in each inclusion complex, or $0.09 \mathrm{mg} \mathrm{kg}^{-1} \mathrm{CAP}$ ) on the pressor response caused by the infusion of angiotensin I on the MAP of conscious rats in comparison with CAPfree infusions.

Complexes of CAP with $\alpha$ - and $\beta$-CD showed a long-lasting inhibitory effect when compared with CAP $(P<0.05)$. The inclusion complex CAP/ $\beta-\mathrm{CD}: \mathrm{SD}$ (illustrated in red) presented a similar time course to that of CAP, evoking a maximum inhibitory effect at 30 minutes. This inhibitory effect was still evident until the end of the experimental period (120 minutes showed).

Table 4 Maximum percent changes in MAP following captopril and captopril/cyclodextrin complexes $\left(0.09\right.$ and $0.5 \mathrm{mg} \mathrm{kg}^{-1}$ of captopril in each complex) administration

\begin{tabular}{|c|c|c|c|c|}
\hline \multirow{2}{*}{$\begin{array}{l}\text { Inclusion } \\
\text { complex }\end{array}$} & \multicolumn{2}{|c|}{$0.09 \mathrm{mg}$ (CAP) $\mathrm{kg}^{-1}$} & \multicolumn{2}{|c|}{$0.5 \mathrm{mg}$ (CAP) $\mathrm{kg}^{-1}$} \\
\hline & $\%$ & $\begin{array}{l}\text { Time } \\
\text { (min) }\end{array}$ & $\%$ & $\begin{array}{l}\text { Time } \\
\text { (min) }\end{array}$ \\
\hline $\mathrm{CAP} / \beta-\mathrm{CD}: \mathrm{SD}$ & $71 \pm 7^{*}$ & 30 & $75 \pm 2$ & 30 \\
\hline CAP/ $\beta-C D: F D$ & $67 \pm 14$ & 30 & $60 \pm 14$ & 45 \\
\hline CAP/ $\beta-C D: V E$ & $58 \pm 5$ & 15 & $65 \pm 15$ & 45 \\
\hline CAP//-CD:KM & $67 \pm 8$ & 45 & $80 \pm 6$ & 60 \\
\hline CAP/ $\alpha-C D: K M$ & $80 \pm 9 *$ & 30 & $87 \pm 6 *$ & 60 \\
\hline $\mathrm{CAP} / \alpha-\mathrm{CD}: \mathrm{SD}$ & $66 \pm 12$ & 45 & $78 \pm 7$ & 60 \\
\hline Captopril & $53 \pm 8$ & 15 & $66 \pm 10$ & 30 \\
\hline
\end{tabular}

Note: $* P<0.05$ when compared to captopril. Data presented as mean \pm SD.
Table 4 shows the maximum percent changes of the angiotensin I pressor effect for the various investigated CAP formulations. These values were collected at the time when maximum reductions in MAP were observed after inclusion complex or CAP administration $\left(0.09\right.$ and $0.5 \mathrm{mg} \mathrm{kg}^{-1}$ of $\mathrm{CAP}$ in each case). At both doses, $\mathrm{CAP} / \alpha-\mathrm{CD}: \mathrm{KM}$ was the most potent inhibitor of the pressor effect of angiotensin I. Also, the inhibitory effect of CAP/ $\alpha-\mathrm{CD}: \mathrm{KM}$ was significantly different from that of CAP $(P<0.05)$.

Three complexes, CAP/ $\beta-\mathrm{CD}: \mathrm{SD}, \mathrm{CAP} / \beta-\mathrm{CD}: \mathrm{VE}$, and $\mathrm{CAP} / \alpha-\mathrm{CD}: \mathrm{KM}$, evoked a maximum response at 15 minutes, 45 minutes, and 60 minutes, respectively. A reduction of this effect was observed at 90 minutes, 75 minutes, and 105 minutes, respectively (data not shown). CAP caused maximum inhibitory response at 30 minutes after injection, showing a reduction of its inhibitory effect 75 minutes after administration. Although all investigated complexes showed longer-lasting inhibitory effects when compared with CAP $(P<0.05)$, two formulations, CAP $/ \alpha-\mathrm{CD}: \mathrm{KM}$ and CAP $/ \beta-$ $\mathrm{CD}: \mathrm{SD}$, exhibited the best results. The CAP/ $\beta-\mathrm{CD}: \mathrm{SD}$ (red, Figure $8 \mathrm{~A}$ ) and $\mathrm{CAP} / \alpha-\mathrm{CD}: \mathrm{KM}$ (blue, Figure $8 \mathrm{~A}$ ) complexes evoked a maximum inhibitory effect on the pressor response evoked by angiotensin I at 30 minutes. However, a decay of this effect was observed from 60 minutes to 90 minutes for CAP/ $\beta-C D: S D$ (red, Figure $8 A$ ). The maximum response of the complex $\mathrm{CAP} / \alpha-\mathrm{CD}: \mathrm{KM}$ started at 30 minutes following its administration, showing a stable inhibitory effect up to the end of the observation period (blue, Figure 8A). Moreover, this effect was detected even 22 hours after CAP/ $\alpha-C D: K M$ administration, indicating a very long-lasting pressor effect on angiotensin I, as if CAP in this formulation was protected from degradation 
and liberated in portions during MAP monitoring. In all experiments, free CAP showed a maximum inhibitory response at 30 minutes after injection. A gradual reduction of its inhibitory effect was observed 45 minutes after administration (Figure 8B).

Therefore, the in vivo results showed relevant information about the activity of CAP and the CD inclusion complexes. Moreover, the methodology used in our study allowed the evaluation of the effectiveness of different inclusion complexes. Two of them, CAP/ $\alpha-\mathrm{CD}: \mathrm{KM}$ and $\mathrm{CAP} / \beta-\mathrm{CD}: \mathrm{SD}$, showed potent and long-lasting inhibitory activity over the pressor response of angiotensin I. These two compounds should be further evaluated in chronic studies aimed at clinical applications.

\section{Final remarks}

In this report, we have provided detailed physicochemical characterization of inclusion compounds formed through different procedures between CAP and three different CDs, and showed that the kneading method resulted in the best inclusion organization for the CAP/ $\alpha-\mathrm{CD}: \mathrm{KM}$ nanoparticles. This formulation showed the highest degree of complexation (superior to $34 \%$ ), and then data collected enabled us to propose a solid model for the inclusion complexes that describes all supramolecular interactions acting between CAP and $\alpha-C D$. NMR data, such as ROESY and DOSY, were very informative and indicated that even hydrophilic species such as CAP are involved in CD cavities in water solution, including self-assembly. Although self-assemblies between CD and CAP gave good complexation results, two inclusion complex formulations seem to additionally complex CAP and explain in vivo bioactivity data. Two formulations exhibited long-lasting effects in controlling angiotensin I pressor effect, especially the inclusion complexes CAP/ $\alpha-\mathrm{CD}: \mathrm{KM}$ formulation. Therefore, this could be a new way for CAP administration that may provide better quality of life for people suffering from high blood pressure, who compose around $25 \%$ of the world's population.

\section{Acknowledgment}

There was financial support from Fundação de Amparo à Pesquisa do Estado de São Paulo, Conselho Nacional de Desenvolvimento Científico e Tecnológico, and Coordenação de Aperfeiçoamento de Pessoal de Nível Superior. Professor Carol H Collins (Instituto de Química (UNICAMP)) is gratefully acknowledged for helpful suggestions on English grammar and style.

\section{Disclosure}

No conflicts of interest were declared in relation to this paper.

\section{References}

1. Liebau G. Captopril in congestive heart failure. Klinische Wochenschrift. 1982;60:107-113.

2. Cheng WT, Wang SL, Lin SY. Solid-state interaction study on the captopril/lubricants systems accelerated by grinding process. $J$ Phys Chem Sol. 2008;69:1007-1016.

3. Nur AO, Zhang JS. Captopril floating and/or bioadhesive tablets: design and release kinetics. Drug Dev Ind Pharm. 2000;26:965-969.

4. Khan MA, Sastry SV, Vaithiyalingam SR, et al. Captopril gastrointestinal therapeutic system coated with cellulose acetate pseudolatex: evaluation of main effects of several formulations variables. Int J Pharm. 2000;193:147-156.

5. Jiménez-Martínezb I, Quirino-Barreda T, Villafuerte-Robles L. Sustained delivery of captopril from floating matrix tablets. Int J Pharm. 2008;362:37-43.

6. Nur AO, Zhang JS. Recent progress in sustained/controlled oral delivery of captopril: an overview. Int J Pharm. 2000b;194:139-146.

7. Loftsson T, Duchêne D. Cyclodextrins and their pharmaceutical applications. Int J Pharm. 2007;329:1-11.

8. Tanaka T, Azevedo MBM, Duran N, et al. Colorectal cancer chemoprevention by $2 \beta$-cyclodextrin inclusion compounds of auraptene and 4'-geranyloxyferulic acid. Inter J Cancer. 2010;126:830-840.

9. Meissner Y, Lamprecht A. Alternative drug delivery approaches for the therapy of inflammatory bowel disease. J Pharm Sci. 2008;97:2878-2891.

10. Davis ME, Brewster ME. Cyclodextrin-based pharmaceutics: past, present and future. Nat Rev Drug Discovery. 2004;3:1023-1035.

11. De Azevedo MBM, Alderete JB, Lino ACS, et al. Biological activities of violacein, a new antitumoral indol derivative, in an inclusion complex with $\beta$-cyclodextrin. J Inclusion Phenom Macrocyclic Chem. 2000;37:93-101.

12. Corrêa DH, Melo PS, de Carvalho CA, et al. Dehydrocrotonin and its beta-cyclodextrin complex: cytotoxicity in V79 fibroblasts and rat cultured hepatocytes. Eur J Pharmacol. 2005;510:17-24.

13. Melo PS, Justo GZ, de Azevedo MBM, et al. Violacein and its $\beta$-cyclodextrin complexes induce apoptosis and differentiation in HL60 cells. Toxicology. 2003;186:217-225.

14. Hirayama F, Uekama K. Cyclodextrin-based controlled drug release system. Adv Drug Deliv Rev. 1999;36:125-141.

15. Keipert S, Fedder J, Böhm A, Hanke B. Interactions between cyclodextrins and pilocarpine: as an example of hydrophilic drug. Int J Pharm. 1996;142:153-162.

16. Vyas A, Saraf S, Saraf S. Cyclodextrin based novel drug delivery systems. J Inclusion Phenom Macrocyclic Chem. 2008;62:23-42.

17. Ikeda Y, Kimura K, Hirayama F, et al. Controlled release of a watersoluble drug, captopril, by a combination of hydrophilic and hydrophobic derivatives. J Control Release. 2000;66:271-280.

18. Ikeda $\mathrm{Y}$, Motoune S, Matsuoka T, et al. Inclusion complex formation of captopril with $\alpha$ - and $\beta$-cyclodextrins in aqueous solution: NMR spectroscopic and molecular dynamic studies. J Pharm Sci. 2002;91:2390-2398.

19. Santos RAS, Campagnole-Santos MJ, Pinheiro SVB, Ferreira AJ. The renin-angiotensin system: emerging concepts. Curr Hypertens Rev. 2006;2:219-226.

20. Cruz JR, Becker BA, Morris KF, Larive CK. NMR characterization of the host-guest inclusion complex between beta-cyclodextrin and doxepin. Magn Reson Chem. 2008;46:838-845.

21. Meier MM, Luiz MTB, Farmer PJ, Szpoganicz B. The influence of $\beta$ - and $\gamma$-cyclodextrin cavity size on the association constant with decanoate and octanoate anions. $J$ Inclusion Phenom Macrocyclic Chem. 2001;40:291-295. 
22. Schneider H-J, Hacket F, Rüdiger V, Ikeda H. NMR studies of cyclodextrins and cyclodextrin complexes. Chem Rev. 1998;98:1755-1786.

23. Calderini A, Pessine FBT. Synthesis and characterization of inclusion complex of the vasodilatador drug minoxidil with $\beta$-cyclodextrin. J Incusion Phenom Macrocyclic Chem. 2008;60:369-377.

24. Rymdém R, Carlfors J, Stilbs P. Substrate binding to cyclodextrins in aqueous solution: a multicomponent self diffusion study. J Inclusion Phenom Macrocyclic Chem. 1983;1:159-168.

25. Lin M, Jayawickrama DA, Rose RA, et al. Nuclear magnetic resonance spectroscopic analysis of the selective complexation of the cis and trans isomers of phenylalanylproline by $\beta$-cyclodextrin. Anal Chim Acta. 1995;307:449-457.

26. Hassan M, Suleiman M, Najib N. Improvement of the in vitro dissolution characteristics of famotidine by inclusion in $\beta$-cyclodextrin. Int J Pharm. 1990;58:19-24.
27. Perdomo-López I, Rodríguez-Pérez AI, Yzquierdo-Peiro JM, et al. Effect of cyclodextrins on the solubility and antimycotic activity of sertaconazole: experimental and computacional studies. J Pharm Sci. 2002;91:2408-2415.

28. Cabral Marques H, Hadgraft J, Kllaway I. Studies of cyclodextrin inclusion complexes. I. The salbutamol-cyclodextrin complex as studied by phase solubility and DSC. Int J Pharm. 1990;63:259-266.

29. Esclusa-Diaz M, Torres-Labandeira J, Kata M, Vila-Jato J. Inclusion complexation of glibenclamide with 2-hydroxypropyl-b-cyclodextrin in solution and in solid state. Eur J Pharm Sci. 1994;1:291-296.

30. Figueiras A, Ribeiro L, Torres-Labandeira, J, Veiga FJB. Evaluation of host-guest complex formation between a benzimidazolic derivative and cyclodextrins by UV-VIS spectrophotometry and differential scaning calorimetry. J Inclusion Phenom Macrocyclic Chem. 2007; $57: 531-535$.

\section{Publish your work in this journal}

The International Journal of Nanomedicine is an international, peerreviewed journal focusing on the application of nanotechnology in diagnostics, therapeutics, and drug delivery systems throughout the biomedical field. This journal is indexed on PubMed Central, MedLine, CAS, SciSearch ${ }^{\circledR}$, Current Contents ${ }^{\circledR} /$ Clinical Medicine,
Journal Citation Reports/Science Edition, EMBase, Scopus and the Elsevier Bibliographic databases. The manuscript management system is completely online and includes a very quick and fair peer-review system, which is all easy to use. Visit http://www.dovepress.com/ testimonials.php to read real quotes from published authors. 